\title{
Occurrence of Meloidogyne fallax in North America, and Molecular Characterization of M. fallax and M. minor from U.S. Golf Course Greens
}

Claudia Nischwitz, Department of Biology, Utah State University, Logan 84322; Andrea Skantar, Zafar A. Handoo, and Maria N. Hult, United States Department of Agriculture-Agricultural Research Service, Nematology Laboratory, Beltsville, MD 20705; and Mark E. Schmitt and Michael A. McClure, School of Plant Sciences, The University of Arizona, Tucson 85721

\begin{abstract}
Nischwitz, C., Skantar, A., Handoo, Z. A., Hult, M. N., Schmitt, M. E., and McClure, M. A. 2013. Occurrence of Meloidogyne fallax in North America, and molecular characterization of M. fallax and M. minor from U.S. golf course greens. Plant Dis. 97:1424-1430.

Several species of root-knot nematodes (Meloidogyne spp.) are known to have significant presence on turfgrass in golf course greens, particularly in the western United States. Nematodes isolated from a golf course in King County, WA were identified as Meloidogyne minor based on analysis of the large ribosomal subunit (LSU 28S D2-D3 expansion segment), the internal transcribed spacers 1 and 2 (ITS rDNA), the intergenic spacer region 2 (IGS2), and the nuclear proteincoding gene Hsp90. Sequence-characterized amplified region (SCAR) primers that were originally designed to be specific for M. fallax were found to cross-react with M. minor. A population from California was

determined to be $M$. fallax based on juvenile tail morphology and analysis of the ribosomal markers and Hsp90, comprising the first report of this species in North America. Using trees based on Hsp90 genomic alignments, the phylogenetic relationships of these populations and known root-knot nematode species were congruent with previous trees based on ribosomal genes. Resolution of M. fallax and $M$. chitwoodi using Hsp90 was equivalent to species separation obtained with $28 \mathrm{~S}$ or $18 \mathrm{~S}$ rDNA alignments. The strengths and weaknesses of ribosomal and Hsp90 markers, and the use of SCAR polymerase chain reaction as diagnostic tools are discussed.
\end{abstract}

In recent years, root-knot nematodes (Meloidogyne spp.) have emerged as an important problem on golf course greens in the western United States. Meloidogyne minor Karssen et al., 2004 has been associated with yellow patch disease on creeping bent grass (Agrostis stolonifera var. stolonifera L.) (15). This nematode has been found in the U.K., the Netherlands, and Belgium, occurring in pastures, golf courses, football pitches, and dunes $(17,27,30)$. Within the Western Hemisphere, M. minor was first discovered on golf course greens in the state of Washington in 2010 (19). In greenhouse tests, $M$. minor reproduced on several economically important crops, including potato (Solanum tuberosum L.), alfalfa (Medicago sativa L.), lettuce (Lactuca sativa L.), oat (Avena sativa L.), tomato (Solanum lycopersicum L.), vetch (Vicia sativa L.), Italian ryegrass (Lolium multiflorum Lamk.), and carrot (Daucus carota L.) (15). It failed to reproduce on marigold (Tagetes patula L.) and maize (Zea mays L.). A study in the Netherlands was conducted to evaluate the host range of several crops for $M$. minor and its damage potential in potato fields (26). Potato was the only crop that supported significant reproduction of $M$. minor in that final population densities exceeded that of initial population. However, annual ryegrass also supported population densities that were higher than the fallow treatment, although densities were low.

Meloidogyne fallax Karssen, 1996 (13) was initially detected in the Netherlands in 1992, first described as a variant population of Meloidogyne chitwoodi Golden et al., 1980 (28). It has since been found on potato in the Netherlands, France, New Zealand, Aus-

Corresponding author: A. M. Skantar,

E-mail: andrea.skantar@ars.usda.gov

Mention of trade names or commercial products in this publication is solely for the purpose of providing specific information and does not imply recommendation or endorsement by the U.S. Department of Agriculture.

Accepted for publication 7 May 2013.

http://dx.doi.org/10.1094/PDIS-03-13-0263-RE

This article is in the public domain and not copyrightable. It may be freely reprinted with customary crediting of the source. The American Phytopathological Society, 2013. tralia, and South Africa $(7,11,18,21)$. M. chitwoodi is another nematode of importance on potato, particularly in the Pacific Northwest region of the United States, where it was first described in 1980 (8). This nematode has also been reported in Argentina, Belgium, Germany, the Netherlands, Portugal, Mexico, and South Africa $(1,6,7,14,29,31)$. The damage caused by $M$. minor on potato is similar to that caused by the quarantine nematodes $M$. chitwoodi and M. fallax; therefore, it is also considered an organism of regulatory importance in the United States, Europe, and many other countries $(1,5)$.

During a survey of golf course greens from 2008 to 2011, we previously identified five Meloidogyne species from seven western states: $M$. chitwoodi, $M$. graminis, $M$. marylandi, $M$. minor, and $M$. naasi (19). M. fallax was not found on the 238 golf courses included in that survey. Late in 2011, samples were received from golf courses in King County, WA and San Francisco County, CA containing infective juveniles (J2) that morphologically resembled M. fallax. Molecular analyses of those samples are described herein. The Washington isolate is here identified as M. minor. The California isolate is identified as $M$. fallax, representing the first report of this nematode within North America and the United States.

\section{Materials and Methods}

Nematodes were extracted from the soil under an intermittent mist for $72 \mathrm{~h} ; \mathrm{J} 2$ and males were collected and concentrated on a 500 -mesh $(25 \mu \mathrm{m})$ sieve. Males were included when present, since they are not frequently found and can be diagnostic for some species. Males and J2 were hand-picked for DNA sequencing and/or fixation for light microscopy. Juveniles for light microscopy were fixed in cold $4 \%$ formalin and $1 \%$ glutaraldehyde in $0.01 \mathrm{M}$ phosphate buffer, $\mathrm{pH} 7.3$, and stored at $4^{\circ} \mathrm{C}$. Juveniles were then processed to anhydrous glycerin by the Seinhorst rapid method (23) and mounted on glass slides. Photomicrographs of J2 (Fig. 1) were taken with a Q-Imaging Color Digital Camera attached to a Leica Leitz DMRB compound microscope at $\times 1,000$ magnification under an oil immersion objective, and measurements (Table 1) were made with an ocular micrometer on the same microscope.

Specimens for sequencing were placed in DESS (33) and stored at $4{ }^{\circ} \mathrm{C}$ for up to a year. For molecular analysis, males and J2s were 
rinsed for $20 \mathrm{~min}$ in sterile distilled water, transferred individually into a $10-\mu \mathrm{l}$ drop of sterile lysis buffer $(10 \mathrm{mM}$ Tris, $\mathrm{pH} 8.0,0.25$ M GuHCl, $0.25 \%$ Triton X-100, $0.25 \%$ Tween 20, $2.0 \mu \mathrm{l}$ of Proteinase K: 934 units per milliliter) on a clean glass coverslip and cut open with a sharp scalpel blade (19). The lysis buffer with the two sections of the nematode was transferred to a sterile, $0.6-\mathrm{ml}$ polymerase chain reaction (PCR) tube containing $30 \mu \mathrm{l}$ of the same buffer. Lysis was completed by incubating the tubes at $60^{\circ} \mathrm{C}$ for $20 \mathrm{~min}$ followed by $10 \mathrm{~min}$ at $98^{\circ} \mathrm{C}$ to inactivate the Proteinase K.

Sequences of PCR primers used in this study are listed in Table 2. Sequence-characterized amplified region (SCAR)-PCR to distinguish $M$. chitwoodi from $M$. fallax included the $M$. fallax-specific primers $\mathrm{Ff}$ and $\mathrm{Rf}$, or the M. chitwoodi-specific primers Fc and Rc, as described by Zijlstra (34). Additional molecular identification was based on analysis of four genes. Ribosomal (rRNA) markers examined were the large ribosomal subunit 28S D2-D3 expansion segment (LSU), amplified with primers D2A and D3B; the internal transcribed spacer region (ITS1-5.8S-ITS2), amplified with primers F195 and 5367; and the intergenic spacer (IGS2), amplified with primers $5 \mathrm{~S}$ and $18 \mathrm{~S}$. A partial fragment of the gene encoding heat shock protein (Hsp90) was also analyzed. Amplification of the D2-D3 and ITS regions consisted of $5 \mu \mathrm{l} 10 \times$ PCR buffer, $5 \mu \mathrm{l} \mathrm{Q}$ solution, $1 \mu \mathrm{d}$ dNTPs (10 $\mathrm{mM}$ per nucleotide), $1 \mu \mathrm{l}$ primer 1 (10 $\mu \mathrm{M}), 1 \mu \mathrm{l}$ primer $2(10 \mu \mathrm{M}), 0.25 \mu \mathrm{l} \mathrm{Taq}, 31.75 \mu \mathrm{l}$ nuclease-free water, and $5 \mu \mathrm{l}$ of DNA in a reaction volume of $50 \mu \mathrm{l}$. For the $28 \mathrm{~S}$ and ITS rRNA genes, cycling conditions were $94^{\circ} \mathrm{C}$ for $3 \mathrm{~min}$, followed by 40 cycles of $94^{\circ} \mathrm{C}$ for $1 \mathrm{~min}, 52^{\circ} \mathrm{C}$ for $1 \mathrm{~min}$, and $72^{\circ} \mathrm{C}$

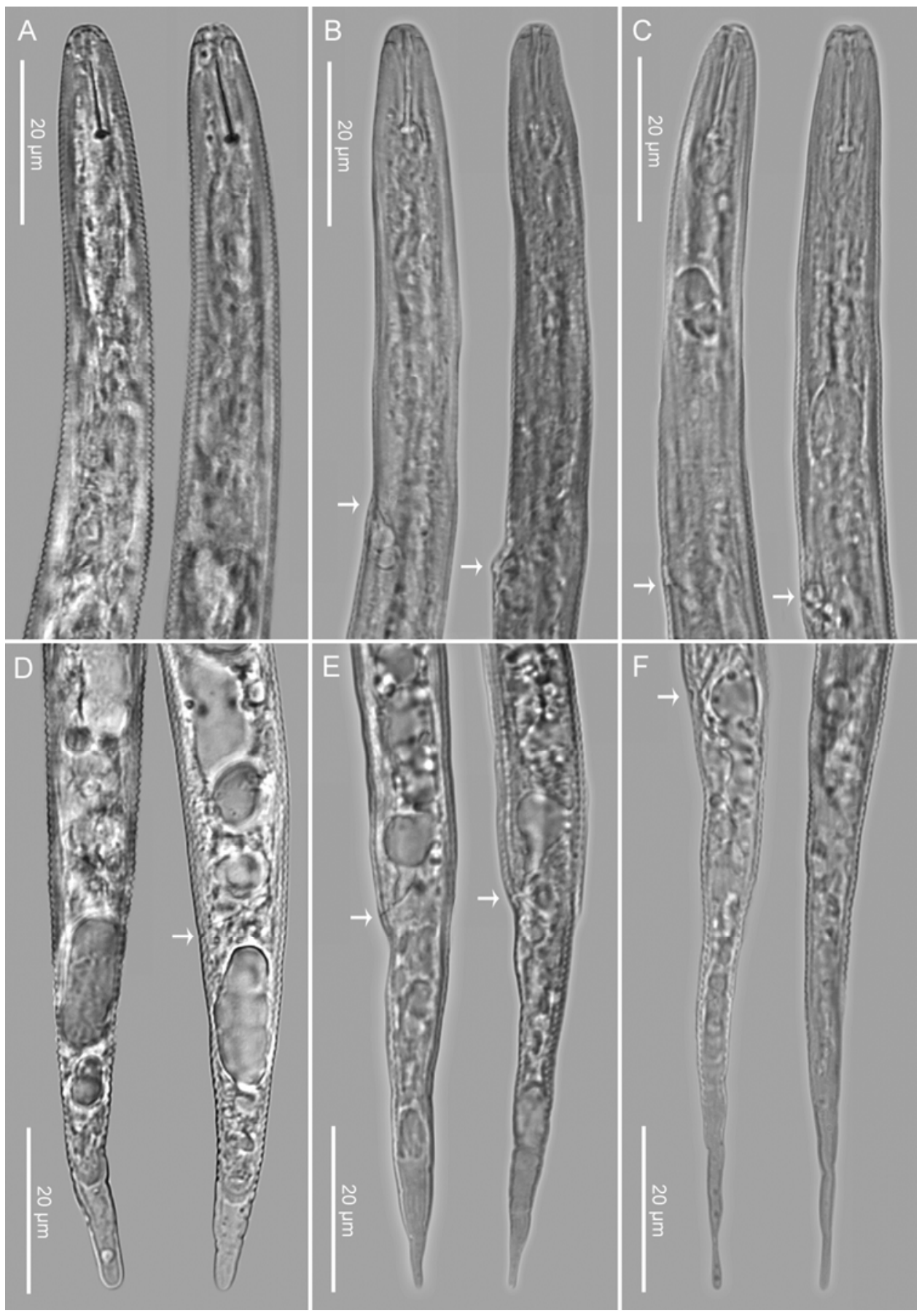

Fig. 1. Photomicrographs of second-stage juveniles of Meloidogyne fallax, M. minor, and M. naasi. A, M. fallax anterior regions showing stylet and part of esophagus. D, Tails with arrow showing anus. B and E, M. minor from Echo Falls, WA: B, anterior regions showing stylet and part of esophagus with arrows showing excretory pores; $E$, tails with arrows showing anal areas. C and F, M. naasi from Echo Falls, WA: C, anterior regions showing stylet and part of esophagus with arrows showing excretory pores; F, tails with arrow showing anus. 
for $1 \mathrm{~min}$, with a final extension at $72^{\circ} \mathrm{C}$ for $10 \mathrm{~min}$. PCR products were visualized on a $1.0 \%$ agarose gel stained with ethidium bromide. PCR reactions for amplification of the IGS2 region consisted of $1.5 \mathrm{mM} \mathrm{MgCl} 2,0.2 \mathrm{mM}$ dNTPs, $0.5 \mu \mathrm{M}$ primer $5 \mathrm{~S}, 0.5 \mu \mathrm{M}$ primer $18 \mathrm{~S}, 1 \mathrm{U}$ Platinum Taq, $3 \mu \mathrm{l}$ DNA extract, and $1 \times$ Taq enzyme buffer in a reaction volume of $25 \mu \mathrm{l}$. Cycling conditions were $94^{\circ} \mathrm{C}$ for $2 \mathrm{~min}$, followed by 45 cycles of $94^{\circ} \mathrm{C}$ for $30 \mathrm{~s}, 53^{\circ} \mathrm{C}$ for $30 \mathrm{~s}$, and $72^{\circ} \mathrm{C}$ for $90 \mathrm{~s}$, ending with a final extension at $72^{\circ} \mathrm{C}$ for 7 min (2). Amplification of Hsp90 consisted of $1.5 \mathrm{mM} \mathrm{MgCl}_{2}, 0.2$ mM dNTPs, $0.5 \mu \mathrm{M}$ primer RKN-d1F, $0.5 \mu \mathrm{M}$ primer RKN-5R, 1 U Platinum Taq, $3 \mu \mathrm{l}$ DNA extract, and $1 \times$ Taq enzyme buffer in a reaction volume of $25 \mu \mathrm{l}$. Cycling conditions were $94^{\circ} \mathrm{C}$ for $2 \mathrm{~min}$, followed by 40 cycles of $94^{\circ} \mathrm{C}$ for $30 \mathrm{~s}, 55^{\circ} \mathrm{C}$ for $20 \mathrm{~s}$, and $68^{\circ} \mathrm{C}$ for $90 \mathrm{~s}$ with a final extension at $68^{\circ} \mathrm{C}$ for $5 \mathrm{~min}$. PCR products for 28S and ITS were extracted from the agarose gels with the QiaQuick Gel extraction kit (Qiagen, Valencia, CA) following the manufacturer's protocol, and the samples were sequenced at the University of Arizona Genetics Core Facility. IGS2 and Hsp90 products were sequenced at the University of Maryland Center for Biosystems Research. New sequences were submitted to GenBank under the accession numbers KC262220-KC262264 (Table 3).

All sequences were compared with GenBank entries using BLASTn and aligned with sequences of authenticated specimens of Meloidogyne species (19). Multiple sequence alignments were performed in Geneious v. 6.0 (Biomatters Ltd., Auckland, NZ) using the MAFFT algorithm (16). Neighbor-joining phylogenetic trees for Hsp90 were made from the consensus alignment of 1,074 bp using the Tamura-Nei (TN) model for genetic distance, with Meloidogyne hapla (AY528416, AY528417) as the outgroup. Trees were resampled with 1,000 bootstrap replicates. Maximum parsimony trees were constructed in PAUP v 4.0d125, employing tree bisection-reconnection (TBR) branch swapping, and accelerated transformation (ACCTRAN) character state optimization with 1,000 bootstrap replicates.

\section{Results}

Molecular characterization of $M$. minor from King County, WA. Preliminary identification of the population from King County, WA as M. fallax was based on morphology of the infective J2. Subsequently, PCR of a SCAR was performed to confirm the morphological diagnosis (34). Using DNA extracted from J2 of the Washington isolate, amplification with $M$. fallax-specific SCAR primers $\mathrm{Ff}$ and $\mathrm{Rf}$ yielded a 530-bp product (Fig. 2A, lanes 2 to 7 and 2B, lanes 7 to 10), while no amplification occurred with the $M$. chitwoodi-specific primers Fc and Rc (not shown). Primers Ff and Rf were also tested in PCR with J2 from an authenticated population of $M$. minor (Fig. 2B, lanes 2 to 6 ); this reaction yielded the same sized product that was obtained from authenticated $M$. fallax (Fig. 2A, lane 9). As expected, SCAR PCR with the M. fallaxspecific primers yielded no products when performed with J2 DNA from authenticated populations of $M$. naasi, M. chitwoodi, $M$. graminicola, $M$. graminis, and $M$. marylandi (data not shown).

Due to the unexpected results obtained from SCAR PCR, further molecular sequencing was undertaken to identify the Washington isolate. The 28S rRNA D2-D3 expansion segment was amplified from males and juveniles; these PCR products were subjected to direct sequencing and aligned with those from sequences from $M$. minor, M. fallax, and M. chitwoodi. The Washington isolate $28 \mathrm{~S}$ was nearly identical to six other M. minor sequences (JN019322, JN019323, JN019324, JN628436, JN157846, and JN628437) differing at 0 to 2 bp out of 609 bp aligned ( $\geq 99.3 \%$ identical). The sequences were clearly distinct from $M$. fallax (JN157848 and FN429017), differing at 39 to $40 \mathrm{bp}$ (6.4 to 6.5\%), and from $M$. chitwoodi (JN019321 and AF435802), differing at 42 to $47 \mathrm{bp}(6.9$ to $7.4 \%$ ). Sequence for the internal transcribed spacer region (ITS1 and 2) of rRNA from the Washington population was also consistent with a diagnosis of $M$. minor. A trimmed 557-bp alignment with other M. minor ITS sequences (GU432775, AY281855,

Table 1. Morphometrics of infective second-stage juveniles of Meloidogyne fallax, M. minor, and M. naasi ${ }^{\text {a }}$

\begin{tabular}{|c|c|c|c|}
\hline Characters & $\begin{array}{c}\text { M. fallax } \\
n=11\end{array}$ & $\begin{array}{c}M . \text { minor } \\
n=21\end{array}$ & $\begin{array}{c}\text { M. naasi } \\
n=20\end{array}$ \\
\hline \multicolumn{4}{|l|}{ Linear $(\mu \mathrm{m})$} \\
\hline Body length & $363.7 \pm 9.7(350-381)$ & $323.5 \pm 18.8(300-361)$ & $372.4 \pm 13.5(340-396)$ \\
\hline Maximum body width & $15.3 \pm 0.5(15-16)$ & $11.9 \pm 0.8(10-13)$ & $12.5 \pm 1.1(10.5-14.0)$ \\
\hline Stylet length & $10.3 \pm 0.5(10-11)$ & $9.7 \pm 0.5(9-10)$ & $12.3 \pm 0.4(11-13)$ \\
\hline Esophagus length ${ }^{b}$ & $122.4 \pm 6.1(110-135)$ & $119.8 \pm 10.7(100-139)$ & $126.9 \pm 7.0(115-140)$ \\
\hline Body width at anus & $10.6 \pm 0.5(10-11)$ & $8.7 \pm 0.8(7.5-10)$ & $8.9 \pm 0.9(7.5-10)$ \\
\hline Tail length & $47 \pm 4.0(42-55)$ & $47.1 \pm 3.7(40-51.5)$ & $68.8 \pm 3.4(61.5-75)$ \\
\hline Hyaline tail terminus length & $12.2 \pm 1.3(10.5-15)$ & $14.8 \pm 1.5(12-17.5)$ & $23.6 \pm 2.0(20-27)$ \\
\hline \multicolumn{4}{|l|}{ Ratios } \\
\hline $\mathrm{a}$ & $23.6 \pm 1.1(21.8-25.4)$ & $27.3 \pm 2.0(23.2-32.5)$ & $30.1 \pm 2.7(25.4-35.7)$ \\
\hline $\mathrm{b}$ & $3 \pm 0.2(2.8-3.3)$ & $2.7 \pm 0.4(2.2-3.3)$ & $2.9 \pm 0.2(2.5-3.2)$ \\
\hline $\mathrm{c}$ & $7.7 \pm 0.6(6.5-8.6)$ & $6.9 \pm 0.4(6.4-7.6)$ & $5.4 \pm 0.3(5.1-6.2)$ \\
\hline$c^{\prime}$ & $4.4 \pm 0.3(4.1-5)$ & $5.5 \pm 0.7(4.2-6.4)$ & $7.8 \pm 0.8(6.2-9.3)$ \\
\hline
\end{tabular}

a Mean \pm standard deviation (range). Measurements in $\mu \mathrm{m}$ were made with an ocular micrometer, taken with a Leica Leitz DMRB compound microscope at $\times 1,000$ magnification under an oil immersion objective.

b From lips to base of glands.

Table 2. Primers used for polymerase chain reaction and DNA sequencing

\begin{tabular}{|c|c|c|c|}
\hline Primer & Marker & Sequence $\left(5^{\prime}\right.$ to $\left.3^{\prime}\right)$ & Reference \\
\hline Ff & SCAR & CCAAACTATCGTAATGCATTATT & Zijlstra (34) \\
\hline $\mathrm{Rf}$ & SCAR & GGACACAGTAATTCATGAGCTAG & Zijlstra (34) \\
\hline Fc & SCAR & TGGAGAGCAGCAGGAGAAAGA & Zijlstra (34) \\
\hline $\mathrm{Rc}$ & SCAR & GGTCTGAGTGAGGACAAGAGTA & Zijlstra (34) \\
\hline $\mathrm{D} 2 \mathrm{~A}$ & $28 \mathrm{~S}$ & ACAAGTACCGTGAGGGAAAGTTG & De Ley et al. (3) \\
\hline D3B & $28 \mathrm{~S}$ & TCGGAAGGAACCAGCTACTA & De Ley et al. (3) \\
\hline 5367 & ITS1-2 & TTGATTACGTCCCTGCCCTTT & Schmitz et al. (22) \\
\hline F195 & ITS1-2 & TCCTCCGCTAAATGATATG & Schmitz et al. (22) \\
\hline $5 S$ & IGS2 & TTAACTTGCCAGATCGGACG & Blok et al. (2) \\
\hline $18 \mathrm{~S}$ & IGS2 & TCTAATGAGCCGTACGC & Blok et al. (2) \\
\hline RKN-d1F & Hsp90 & GCYGATCTTGTYAACAACCYTGGAAC & This study \\
\hline RKN-5R & Hsp90 & TCGAACATGTCAAAAGGAGC & This study \\
\hline
\end{tabular}


JN157871, JN157867, EU881694, EU881695, EU881696, and EU878542) showed $>99 \%$ identity (variation at 0 to 2 bp among all sequences), whereas the Washington population ITS sequence showed 41 to $43 \mathrm{bp}$ divergence ( 7.7 to $9 \%$ ) from $M$. fallax ITS (EU252015-EU252017, GU433344, JN157869).

Molecular characterization of $M$. fallax from San Francisco County, CA. Morphologically, J2 from the San Francisco County, CA golf course resembled M. fallax. Comparison of this population with $M$. minor revealed slight differences in the tails between isolates (Fig. 1 and Table 1). Seven individual J2s each from two separate samples were subjected to molecular analysis. Comparison of the 28S D2-D3 region with sequences from GenBank (noted above) revealed near identity to others from M. fallax (0 to $1 \mathrm{bp}$ difference), 8 to $13 \mathrm{bp}$ divergence from $M$. chitwoodi (1.3 to $1.9 \%$ ), and 39 to $42 \mathrm{bp}$ divergence from $M$. minor (6.4 to 7.1\%). Alignment of eight ITS sequences obtained for this population showed $>99 \%$ similarity with five others for $M$. fallax ITS, 17 to $18 \mathrm{bp}$ differences from $M$. chitwoodi (3.3 to $3.9 \%$ ) and 40 to 43 bp differences from $M$. minor (10.5 to $13.9 \%$ ). Testing with the SCAR primers specific for $M$. fallax amplified the expected 515-bp band, but there was no amplification with the $M$. chitwoodi-specific primers (not shown). These molecular results confirm the diagnosis of $M$. fallax and comprise the first report of this species in North America.

Analysis of the ribosomal intergenic spacer region (IGS2) from Meloidogyne spp. Amplification of the IGS2 yielded fragments of 1,600 bp from the California isolate, 1,610 bp from authenticated M. fallax, 1,420 bp from M. chitwoodi, and 1,500 bp from M. minor. Alignment of four sequences from the California population showed greatest $(98.9 \%)$ similarity to $M$. fallax GQ395584 and the sequence from the Netherlands population. Several other $M$. fallax sequences from GenBank were slightly less similar to the California isolate (98.7 to $98.8 \%$ ). The major difference between the four sequences obtained from the California isolate and other M. fallax IGS was a 30-bp region near the $3^{\prime}$ end; the California sequences contained a 6-bp deletion and several base changes compared to $M$. fallax sequence GQ395575 and others. IGS sequences from $M$. chitwoodi reference populations included in this study were $\geq 99.6 \%$ identical to AF013992 and 25 others used for comparison. M. minor IGS showed the greatest amount of intraspecific and interspecific variation. Sequences were obtained from three populations from the U.K. and one from the Netherlands. Pairwise similarities ranged from 94.8 to $99.6 \%$. Again, the major differences among sequences were limited to one area of the sequence; in this case, localized to a 75-bp region starting at base 1270. Sequence from the Lough Erne $M$. minor population had a deletion of 24 bp relative to those from Monkston and Dunmurry Springs; the Netherlands sequence had a 51-bp insertion. Obtaining a clear alignment of these $M$. minor sequences with those from M. fallax and M. chitwoodi was difficult, as there were many base changes and indels among them.

Molecular and phylogenetic analysis based on Hsp90 genomic DNA. A partial fragment of the protein-coding gene Hsp90 was amplified from the Washington $M$. minor and California $M$. fallax populations and from reference populations of $M$. fallax, $M$.
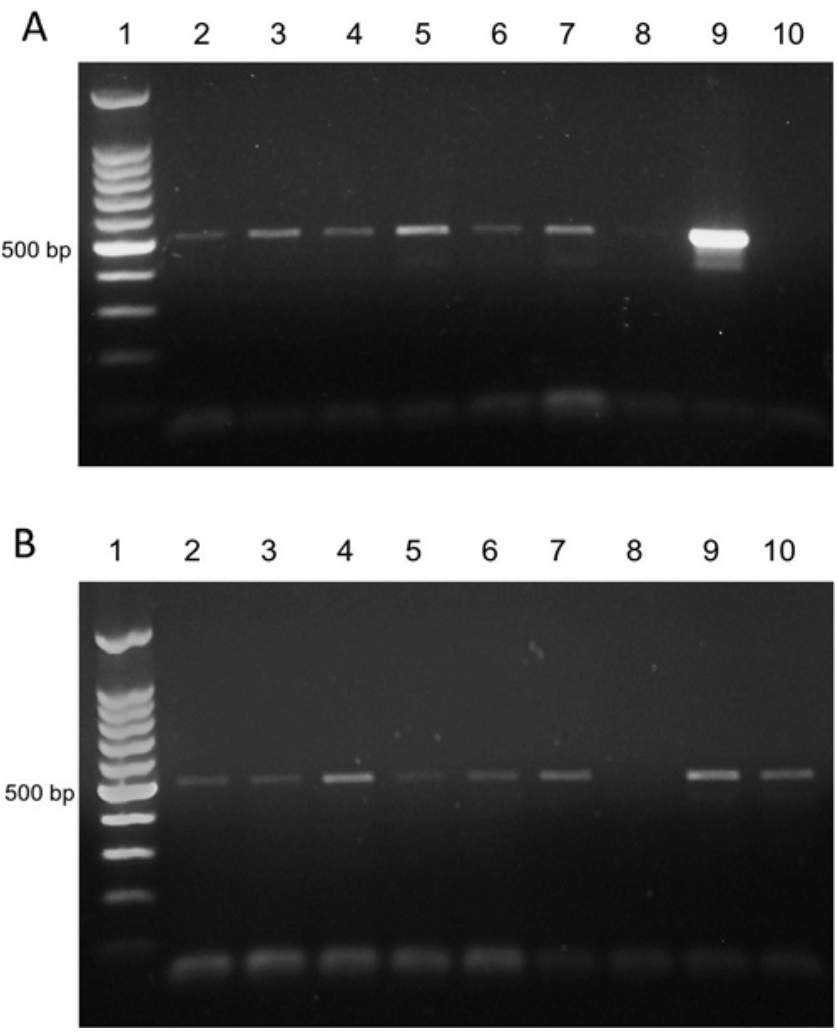

Fig. 2. Sequence-characterized amplified region polymerase chain reaction (SCAR PCR) with Meloidogyne fallax-specific primers with template from M. minor. A, Lane 1: DNA ladder; lanes 2-8: M. minor from Washington; lane 9: M. fallax control; lane 10: negative control. B, Lane 1: DNA ladder; lanes 2-6: M. minor control; lanes 7-10: M. minor from Washington.

Table 3. New molecular sequences obtained from Meloidogyne minor and M. fallax from golf course turf grass and from Meloidogyne spp. reference populations

\begin{tabular}{|c|c|c|c|c|c|c|}
\hline \multirow[b]{2}{*}{ Species } & \multirow[b]{2}{*}{ Pop. } & \multirow[b]{2}{*}{ Origin } & \multicolumn{4}{|c|}{ GenBank accession number } \\
\hline & & & 28S D2-D3 rDNA & ITS-rDNA & IGS2 & Hsp90 \\
\hline \multirow[t]{2}{*}{ Meloidogyne chitwoodi } & $13 \mathrm{~B}$ & Washington, USA & $\begin{array}{l}\text { KC241980- } \\
\text { KC241981 }\end{array}$ & & $\begin{array}{l}\text { KC262254- } \\
\text { KC262255 }\end{array}$ & $\begin{array}{l}\text { KC262220- } \\
\text { KC262224 }\end{array}$ \\
\hline & $10 \mathrm{I} 6$ & Idaho, USA & & & KC262253 & \\
\hline \multirow[t]{4}{*}{ M. fallax } & $\mathrm{HH}$ & Netherlands & & & & \\
\hline & LW & Netherlands & & & KC262264 & $\begin{array}{l}\text { KC26225- } \\
\text { KC262228 }\end{array}$ \\
\hline & 824 & California, USA & $\begin{array}{l}\text { KC241962- } \\
\text { KC241968 }\end{array}$ & $\begin{array}{l}\text { KC241954- } \\
\text { КC241961 }\end{array}$ & & \\
\hline & 853 & California, USA & $\begin{array}{l}\text { KC241969- } \\
\text { КC241975 }\end{array}$ & & $\begin{array}{l}\text { КC262260- } \\
\text { КC262263 }\end{array}$ & $\begin{array}{l}\text { КС262229- } \\
\text { КС262233 }\end{array}$ \\
\hline \multirow[t]{4}{*}{ M. minor } & 202 & United Kingdom & & & KC262256 & KC262242 \\
\hline & 204 & United Kingdom & & & $\begin{array}{l}\text { КC262257- } \\
\text { КC262258 }\end{array}$ & $\begin{array}{l}\text { КC262238- } \\
\text { КC262241 }\end{array}$ \\
\hline & LW & Netherlands & & & KC262259 & $\begin{array}{l}\text { KC262234- } \\
\text { KC262237 }\end{array}$ \\
\hline & 820 & Washington, USA & $\begin{array}{l}\text { KC241976- } \\
\text { KC241978 }\end{array}$ & KC241953 & & $\begin{array}{l}\text { КC262243- } \\
\text { КC262246 }\end{array}$ \\
\hline M. naasi & $12 \mathrm{~A} 5$ & Washington, USA & KC241979 & & & $\begin{array}{l}\text { KC262247- } \\
\text { КC262252 }\end{array}$ \\
\hline
\end{tabular}


minor, M. chitwoodi, and M. naasi. For M. minor Hsp90, intraspecific variation ranged from 1 to $4 \mathrm{bp}$ ( $\geq 99.5 \%$ identity). Conversely, separation between $M$. minor and M. fallax was clear, with the pairwise divergences ranging from 12.5 to $13 \%$. Four cloned Hps 90 sequences representing a population of $M$. chitwoodi were $\geq 99.2 \%$ identical to each other, and the divergence between $M$. fallax and M. chitwoodi Hsp90 ranged from 3.5 to $3.9 \%$. Four Hsp90 sequences obtained from the Washington population were closest to M. minor, diverging at 0 to 11 bp ( 0 to $1.3 \%$ ) across all sequences. Four Hsp90 sequences from the California population were most similar to those from the Netherlands population of $M$. fallax, with variation ranging from 0 to $5 \mathrm{bp}$ among all sequences. Neighbor-joining trees were constructed in Geneious from a genomic sequence alignment of 1,074 characters using the TamuraNei genetic distance model, with $M$. hapla as the outgroup and 1,000 bootstrap replicates (Fig. 3; support values shown above branches). Maximum parsimony analysis was performed for an alignment of 1,074 total characters, of which 320 were parsimony informative. Tree statistics generated in PAUP* were: tree length $=$ 435; consistency index $=0.931034$; retention index $=0.972248$. Parsimony bootstrap support values are shown below the branches in the distance tree.

\section{Discussion}

Females of root-knot nematodes are seldom retrieved from soil samples from turfgrass, and none were available for this study. Initial diagnosis was based on morphology of the J2. Both $M$. fallax and M. minor $\mathrm{J} 2$ were found in greens, primarily Poa апnиa L. that contained M. naasi as the predominant species. M. naasi is easily distinguished from either M. fallax or M. minor on the basis of J2 morphology, its most distinctive characters being the shape and length of the tail (Fig. 1). Morphological differences between $\mathrm{J} 2$ of M. fallax and M. minor are more subtle and, in general, unsuitable for diagnostic purposes due to overlapping measurements of individual specimens (Table 1). Should M. chitwoodi also occur in mixed populations with $M$. fallax, diagnosis based on $\mathrm{J} 2$ morphology would be even more challenging.

While the Washington population resembled M. fallax based on juvenile tail morphology, clear discrimination from $M$. minor and $M$. chitwoodi often required molecular confirmation using either PCR or isozyme identification $(11,12)$. The SCAR PCR assay designed by Zijlstra et al. (34) can distinguish $M$. chitwoodi, $M$. fallax, and M. hapla using species-specific pairs of primers that were based upon randomly amplified polymorphic DNA regions (RAPDs). This assay has become widely used, and is one of the molecular methods recommended by the European and Mediterranean Plant Protection Organization (EPPO) for identification of $M$. fallax and M. chitwoodi (1). The ability of $M$. fallax-specific primers to detect $M$. minor was not anticipated. However, the SCAR assay predates the description of $M$. minor, and there have been no published tests of the assay with this relatively new species. Therefore, the present results have important implications for diagnostic, research, and regulatory purposes. Sole reliance on the previously reported SCAR primers for the identification of M. fallax, a quar-

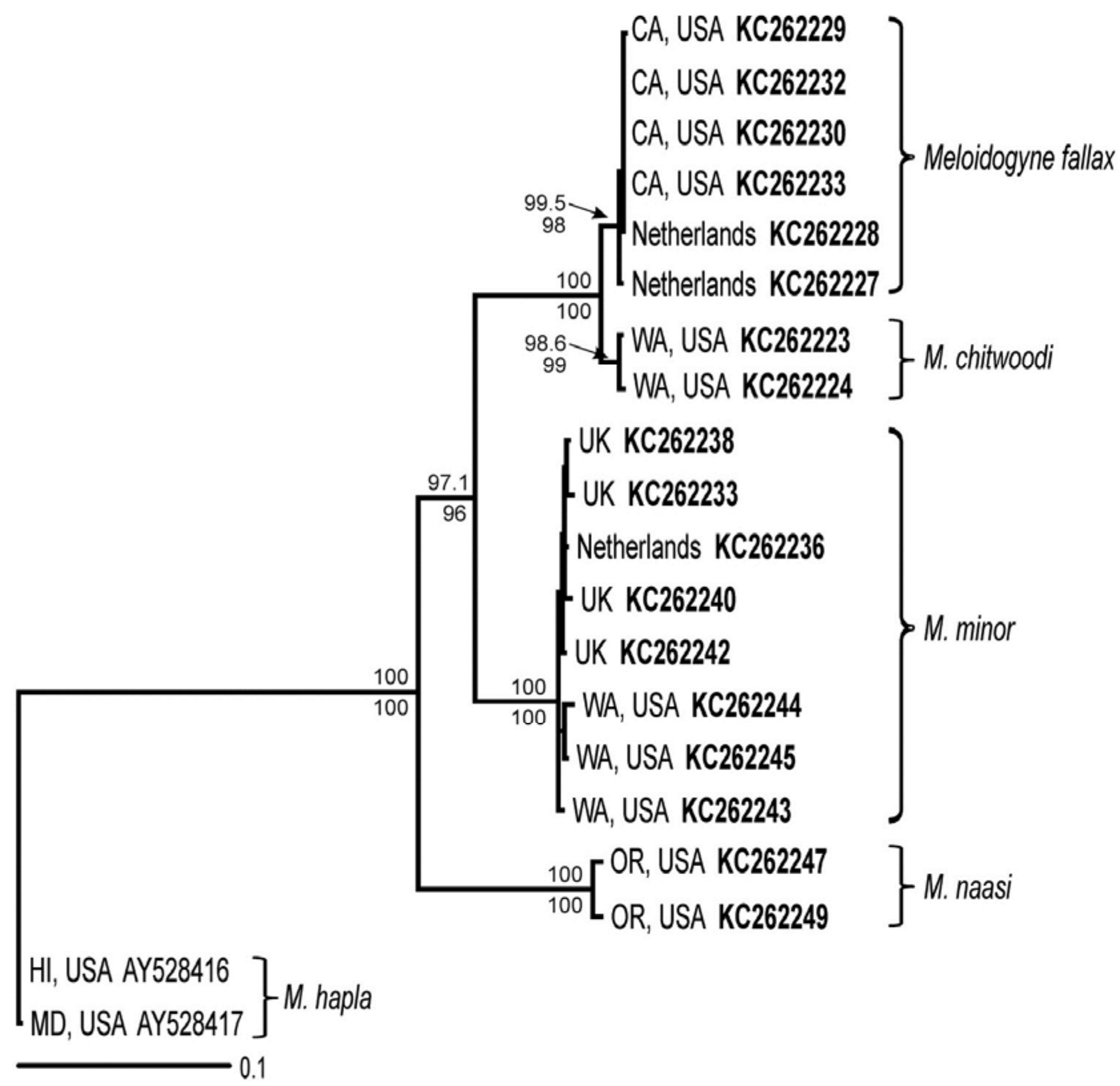

Fig. 3. Neighbor-joining 50\% majority-rule consensus tree based on 1,074-bp alignment of Hsp90 genomic DNA sequences from selected Meloidogyne spp. Bootstrap values from 1,000 replicates are indicated above the branches; bootstrap support values from a maximum parsimony tree constructed for the same alignment (not shown) are indicated below the branches. 
antined species in some countries, is not advisable if $M$. minor is suspected or known to be present.

Identification of the Washington isolate as M. minor was confirmed through analysis of the 28S D2-D3 expansion regions, which had a high degree of similarity with six known populations of M. minor, including others from Washington (U.S.), Belgium, and the U.K. Likewise, ITS rDNA showed near identity with sequences from populations originating from Washington, the Netherlands, and the U.K. Sequences previously reported for M. minor from Washington were also found on golf course turfgrass (19). The California population was identified as M. fallax based on 28S rDNA sequences, having near identity to populations of this species from Belgium and New Zealand. ITS rDNA sequences from the California population also show near identity to M. fallax sequences from Australia, Belgium, and New Zealand. The amount of intraspecific variation was always less than the interspecific variation, giving unambiguous distinction of $M$. fallax and M. minor based on either of these markers.

IGS2 sequences from the Washington and California populations were also consistent with the identification based on the other two ribosomal genes. However, a significant amount of intraspecific variation was detected in this marker, with indels occurring among sequences within both $M$. fallax and $M$. minor. IGS from the latter species was particularly variable among the populations examined from Washington, the Netherlands, and the U.K. The explanation for this variation is not clear, but it renders the IGS less reliable for identification of M. minor than either 28S or ITS.

Hsp90 has been increasingly included in phylogenetic studies of plant-parasitic nematodes $(20,24,25)$ or used for species identification $(9,25)$. Neighbor-joining and maximum parsimony trees based upon Hsp90 genomic DNA alignments from five species of rootknot nematodes agreed with the species relationships in more extensive $28 \mathrm{~S}$ and $18 \mathrm{~S}$ phylogenies. Moreover, the Hsp90 trees showed better separation of $M$. chitwoodi and $M$. fallax than those based on either $18 \mathrm{~S}$ or mitochondrial DNA sequences (19). Variation within introns was higher than in coding regions, and first and second codon positions were generally more conserved than third codon positions. Phylogenies constructed from alignments of coding sequences only (introns removed) had branch support values that were the same or lower than the genomic alignment (not shown). The consistency of Hsp90 tree topologies with those based on ribosomal genes thus provides another option for phylogenetic analysis of the root-knot nematodes.

Many molecular diagnostic techniques have been developed for the identification of $M$. fallax and $M$. chitwoodi, including speciesspecific SCAR PCR (34), multiplex PCR based on ITS rDNA (7), size discrimination of IGS PCR products (32), and ITS-based real time TaqMan PCR (35). Most of these assays have not been reexamined using M. minor, so their specificity may or may not stand the test of time. More recently, Holterman et al. (10) employed high-resolution melting curve (HRMC) analysis based on IGS for identification of M. chitwoodi, M. fallax, and M. hapla and their distinction from tropical root-knot nematodes. These authors did not include $M$. minor in their study, and based upon the intraspecific variation we found in IGS from that species, HRMC of this species could result in false positives. The only test specifically developed for detection of $M$. minor was a real-time PCR assay based on ITS rDNA primers and a fluorescent TaqMan probe (4). The additional sequence information obtained from the U.S. and European populations of $M$. minor should facilitate the design of additional diagnostic tools or procedures for identifying this nematode. For instance, multiplex PCR for simultaneous discrimination of $M$. minor, $M$. fallax, and $M$. chitwoodi would be diagnostically useful for plant quarantine to limit the future spread of these nematodes within the United States.

\section{Acknowledgments}

Partial funding for this research was provided by our respective institutions. Additional support came from industry sources, individual golf courses, and professional golf associations. We thank Joseph Mowery of the USDA ARS Nematology Laboratory for excellent technical assistance.

\section{Literature Cited}

1. Anonymous. 2009. Meloidogyne chitwoodi and Meloidogyne fallax. EPPO Bull. 39:5-17.

2. Blok, V. C., Phillips, M. S., and Fargette, M. 1997. Comparison of sequences from the ribosomal DNA intergenic region of Meloidogyne mayaguensis and other major root knot nematodes. J. Nematol. 29:16-22.

3. De Ley, P., Felix, M. A., Frisse, L. M., Nadler, S. A., Sternberg, P. W., and Thomas, W. K. 1999. Molecular and morphological characterisation of two reproductively isolated species with mirror-image anatomy (Nematoda: Cephalobidae). Nematology 1:591-612.

4. De Weerdt, M., Kox, L., Waeyenberge, L., Viaene, N., and Zijlstra, C. 2011. A real-time PCR assay to identify Meloidogyne minor. J. Phytopathol. 159:80-84.

5. den Nijs, L., and Karssen, G. 2004. Meloidogyne chitwoodi and Meloidogyne fallax. EPPO Bull. 34:315-320.

6. den Nijs, L. J. M. F., Brinkman, H., and Van Der Sommen, A. T. C. 2004. A Dutch contribution to knowledge on phytosanitary risk and host status of various crops for Meloidogyne chitwoodi Golden et al., 1980 and M. fallax Karssen, 1996: An Overview. Nematology 6:303-312.

7. Fourie, H., Zijlstra, C., and McDonald, A. H. 2001. Identification of rootknot nematode species occurring in South Africa using the SCAR-PCR technique. Nematology 3:675-680.

8. Golden, A. M., O'Bannon, J. H., Santo, G. S., and Finley, A. M. 1980. Description and SEM observations of Meloidogyne chitwoodi $\mathrm{n}$. sp. (Meloidogynidae). A root knot nematode on potato in the Pacific Northwest. J. Nematol. 12:319-327.

9. Handoo, Z. A., Skantar, A. M., Carta, L. K., and Schmitt, D. P. 2005. Morphological, molecular evaluation of a Meloidogyne hapla population damaging coffee (Coffea arabica) in Maui, Hawaii. J. Nematol. 37:136-145.

10. Holterman, M. H. M., Oggenfuss, M., Frey, J. E., and Kiewnick, S. 2012. Evaluation of high-resolution melting curve analysis as a new tool for rootknot nematode diagnostics. J. Phytopathol. 160:59-66.

11. Karssen, G. 1994. The use of isozyme phenotypes for the identification of root-knot nematodes (Meloidogyne spp.). Pages 85-88 in: Annual Report 1992 Diagnostic Centre. Plant Protection Service, Wageningen, Netherlands.

12. Karssen, G. 1995. Morphological and biochemical differentiation in Meloidogyne chitwoodi populations in the Netherlands. Nematologica 41:314315 .

13. Karssen, G. 1996. Description of Meloidogyne fallax n. sp. (Nematoda: Heteroderidae), a root-knot nematode from the Netherlands. Fund. Appl. Nematol. 19:593-599.

14. Karssen, G. 2002. The plant-parasitic nematode genus Meloidogyne göldi, 1892 (Tylenchida) in Europe. Brill, Leiden, The Netherlands.

15. Karssen, G., Bolk, R. J., Van Aelst, A. C., Van Den Beld, I., Kox, L. F. F., Korthals, G., Molendijk, L., Zijlstra, C., Van Hoof, R., and Cook, R. 2004. Description of Meloidogyne minor $\mathrm{n}$. sp. (Nematoda: Meloidogynidae), a root-knot nematode associated with yellow patch disease in golf courses. Nematology 6:59-72.

16. Katoh, K., Kazuharu Misawa, K., Kuma, K. I., and Miyata, T. 2002. MAFFT: A novel method for rapid multiple sequence alignment based on fast Fourier transform. Nucleic Acids Res. 30:3059-3066.

17. Lammers, W., Karssen, G., Jelleman, P., Baker, R., Hockland, S., Fleming, C., and Turner, S. 2006. Meloidogyne minor. Pest Risk Assessment. Online publication: http://www.eppo.int/QUARANTINE/Pest_Risk_Analysis/PRA _documents.htm

18. Marshall, J. W., Zijlstra, C., and Knight, K. W. L. 2001. First record of Meloidogyne fallax in New Zealand. Australas. Plant Pathol. 30:283-284.

19. McClure, M. A., Nischwitz, C., Skantar, A. M., Schmitt, M. E., and Subbotin, S. A. 2012. Root-knot nematodes in golf course greens of the Western USA. Plant Dis. 96:635-647.

20. Mundo-Ocampo, M., Troccoli, A., Subbotin, S. A., Del Cid, J., Baldwin, J. G., and Inserra, R. N. 2008. Synonymy of Afenestrata with Heterodera supported by phylogenetics with molecular and morphological characterisation of $H$. koreana comb. n. and H. orientalis comb. n. (Tylenchida: Heteroderidae). Nematology 10:611-632.

21. Nobbs, J. M., Liu, Q., Hartley, D., Handoo, Z. A., Williamson, V., Santo, G., Curran, J., Walker, G., and Taylor, S. 2001. First record of Meloidogyne fallax in Australia. Australas. Plant Pathol. 30:373.

22. Schmitz, B., Burgermeister, W., and Braasch, H. 1998. Molecular genetic classification of Central European Meloidogyne chitwoodi and M. fallax populations. Nachrichtenbl. Deutschen Pflanzenschutzd. 50:310-317.

23. Seinhorst, J. W. 1959. A rapid method for the transfer of nematodes from fixative to anhydrous glycerin. Nematologica 4:67-69.

24. Skantar, A. M., and Carta, L. K. 2004. Phylogenetic evaluation of nucleotide and protein sequences from the heat shock protein 90 gene of selected nematodes. J. Nematol. 36:466-480.

25. Skantar, A. M., Carta, L. K., and Handoo, Z. A. 2008. Molecular and morphological characterization of an unusual Meloidogyne arenaria population from traveler's tree (Ravenala madagascariensis). J. Nematol. 40:179-189.

26. Thoden, T. C., Korthals, G. W., Visser, J., and van Gastel-Topper, W. 2012. A field study on the host status of different crops for Meloidogyne minor and its damage potential on potatoes. Nematology 14:277-284. 
27. Turner, S. J., and Fleming, C. C. 2005. Meloidogyne minor: A threat to temperate crops? Comm. Agric. Appl. Biol. Sci. 70:885-887.

28. Van Meggelen, J. C., Karssen, G., Janssen, G. J. W., Verkerk-Bakker, B., and Janssen, R. 1994. A new race of Meloidogyne chitwoodi? Fund. Appl. Nematol. 17:93.

29. Viaene, N., Mahieu, T., and de la Peña, E. 2007. Distribution of Meloidogyne chitwoodi in potato tubers and comparison of extraction methods. Nematology 9:143-150.

30. Viaene, N. M., Wiseborn, D. B., and Karssen, G. 2007. First report of the rootknot nematode Meloidogyne minor on turfgrass in Belgium. Plant Dis. 91:908.

31. Waeyenberge, L., and Moens, M. 2001. Meloidogyne chitwoodi and M. fallax in Belgium. Nematol. Mediterr. 29:91-97.

32. Wishart, J., Phillips, M. S., and Blok, V. C. 2002. Ribosomal intergenic spacer: A polymerase chain reaction diagnostic for Meloidogyne chitwoodi, M. fallax, and M. hapla. Phytopathology 92:884-892.

33. Yoder, M., De Ley, I. T., King, I. W., Mundo-Ocampo, M., Mann, J., Blaxter, M., Poiras, L., and De Ley, P. 2006. DESS: A versatile solution for preserving morphology and extractable DNA of nematodes. Nematology 8:367-376.

34. Zijlstra, C. 2000. Identification of Meloidogyne chitwoodi, M. fallax and M. hapla based on SCAR-PCR: A powerful way of enabling reliable identification of populations or individuals that share common traits. Eur. J. Plant Pathol. 106:283-290.

35. Zijlstra, C., and Van Hoof, R. A. 2006. A multiplex real-time polymerase chain reaction (TaqMan) assay for the simultaneous detection of Meloido gyne chitwoodi and M. fallax. Phytopathology 96:1255-1262. 